\title{
Estabilidade e adesividade de ligante asfalto modificado com blenda de borra oleosa de petróleo com borracha de pneu
}

\author{
Stability and adhesiveness of modified asphalt \\ binder with oil sludge blend and tire rubber
}

Robson Rabelo de Santana ${ }^{1}$, Rosiane dos Santos ${ }^{2}$, Erinaldo Hilário Cavalcante ${ }^{1}$, Gisélia Cardoso ${ }^{1}$

\footnotetext{
${ }^{1}$ Universidade Federal de Sergipe, Programa de Pós-Graduação em Engenharia Civil, São Cristóvão - SE, 49100-000, e-mail: robsonrabelo_eng.civil@ hotmail.com

${ }^{2}$ Universidade Federal de Sergipe, Depto. Engenharia Química, São Cristóvão - SE, 49100-000

e-mail: rosianebeth@yahoo.com.br, erinaldohc@gmail.com, giselia@ufs.br
}

\begin{abstract}
RESUMO
O revestimento asfáltico de pavimento rodoviário tem por função reduzir as tensões impostas pelo tráfego e oferecer conforto e segurança aos usuários. Dessa forma, estudos para inibir intervenções corretivas em curto prazo e aumentar a sua vida útil são de interesse dos órgãos responsáveis pela sua manutenção. As modificações dos ligantes asfálticos ganha importância neste contexto, tendo em vista conferir maior durabilidade ao revestimento, contudo, fatores como a separação de fases nos ligantes modificados, limitam a modificação em escala industrial. O objetivo deste estudo foi avaliar a estabilidade físico-química e a adesividade do CAP 50/70 modificado com blenda de borra oleosa de petróleo e borracha de pneus, na proporção 85/15\% $\mathrm{m} / \mathrm{m}$ (M1), na presença dos aditivos NPA - Neutro Pesado Aromático e argilas bentonita e caulinita. Para tanto, ensaios de estabilidade de estocagem foram realizados com os ligantes modificados, por medida de viscosidade, a de adesividade conforme a norma 078/98 do DNER. Os resultados mostraram que a adição de $1 \%$ $\mathrm{m} / \mathrm{m}$ de NPA aumenta a estabilidade de estocagem do ligante modificado por M1 e melhora a sua adesividade ao agregado.
\end{abstract}

Palavras-chave: Borra oleosa de petróleo, borracha de pneu, separação de fases, adesividade.

\begin{abstract}
Asphalt road coating pavement has the function of reducing the tensions imposed by the traffic and offer comfort and safety to the users. Thus, studies to inhibit short-term corrective interventions and increase their useful life are of interest to the agencies responsible for their maintenance. Modifications of the asphaltic binders are important in this context, in order to confer greater durability to the coatings, however, factors such as the separation of phases in the modified binders, limit the modification on an industrial scale. The objective of this study was to evaluate the physico-chemical stability and the adhesiveness of the modified CAP 50/70 with oil sludge blend and tire rubber in the proportion of 85/15\% $\mathrm{m} / \mathrm{m}(\mathrm{M} 1)$ in the presence of NPA additives - Neutral Heavy Aromatic and clays bentonite and kaolinite. For this purpose, storage stability tests were carried out with the modified binders, by viscosity measurement, of the adhesiveness according to standard 078/98 of the DNER. The results showed that the addition of $1 \% \mathrm{~m} / \mathrm{m} \mathrm{NPA}$ increases the storage stability of the M1 modified binder and improves its adhesiveness to the aggregate.
\end{abstract}

Keywords: Oily oil sludge, tire rubber, phase separation, adhesiveness.

\section{INTRODUÇÃO}

Das rodovias pavimentadas no Brasil 12,5\% são consideradas de estado ótimo, 30,2\% bom, 34,9\% regular, $16,1 \%$ ruim e $6,3 \%$ péssimo [1] dentre as causas apontadas para esta situção estão o volume de tráfego elevado, bem como cargas transportada acima do admissível por lei [13].

Dentre as possíveis maneiras para elevar a vida útil dos revestimentos, do tipo Concreto Asfáltico Usinado a Quente (CAUQ), está a modificação do ligante. 
Os modificantes de ligantes asfálticos convencionais são os copolímeros estireno-butadieno-estireno (SBS) as borrachas de estireno-butadieno (SBR) e as borrachas moída de pneus. Entretanto, outros modificantes vêm sendo objeto de estudos e de aplicação em campo, como os antioxidantes, as fibras de poliéster e de polipropileno, o copolímero Etil Vinil Acetato (EVA) e o ácido polifosfórico (PPA) [3,7]

O uso de borracha de pneus inservíveis tem destaque no processo de modificação de ligante asfáltico, além de conferir à mistura asfáltica menor deformação permanente e maior resistência à fadiga. A utilização da borracha evita que os pneus sejam dispostos em locais inadequados sendo prejudicial ao meio ambiente[10][2]. A incorporação da borracha ao asfalto requer estudos aprofundados, face à heterogeneidade dos constituintes dos pneus e a tendência de aumento de viscosidade do ligante [10].

Outra linha de estudo, que vem apresentando resultados satisfatórios como modificante de ligante asfáltico, é a pré mistura de borracha de pneus com borra oleosa de petróleo advinda de tratamento primário e de destilaria de petróleo [5].

A borra é gerada durante as etapas de produção, transporte e refino do petróleo e sua composição varia de acordo com a etapa considerada [4]. A borra oleosa de petróleo é um material semissólido composto por uma mistura de argila, sílica, óxidos de ferro, óleos, além de água e produtos químicos usados na produção do petróleo [12].

O aumento da viscosidade e a instabilidade à estocagem são tipos comuns de mudanças que são observadas em ligantes modificados por polímeros e que não são desejáveis. Maior viscosidade faz com que o ligante necessite de maior energia no processamento de sua mistura e compactação, enquanto que a separação de fases impossibilita a estocagem em elevadas temperaturas [9,14].

Os aditivos que proporcionam maior homogeneidade entre polímeros e ligante asfáltico são óleos extensores e reagentes químicos [6]. Com o advento do uso de nanoargilas em modificações asfálticas, tem-se estudado a aplicação de algumas argilas como mecanismo de redução na separação de fases de asfaltos modificados [8,11]. Estudos feitos por [14] demonstraram que há aumento da estabilidade à estocagem quando utilizado asfalto modificado com resíduos de embalagens de polietileno adicionando-se argila bentonítica modificada em pequenos teores.

A boa adesividade do ligante ao agregado está diretamente relacionada à diferença de polaridade destes materiais. Quando a adesividade é baixa, as misturas asfálticas apresentam rápida degradação, tendo em vista o descolamento da película de ligante aderida ao agregado [11]. Quando a interação entre agregado e ligante é insatisfatória, a falha de adesividade é acelerada quando o pavimento é submetido ao contato com a água. Agregados da região nordeste do Brasil apresentam polaridade semelhante ao ligante, logo, o uso de aditivos melhoradores de adesividade torna-se imprescindível.

\section{MATERIAIS E MÉTODOS}

\subsection{Materiais}

Os materiais utilizados neste estudo foram o CAP 50/70, fornecido pela EMURB - Empresa Municipal de Urbanismo do Município de Aracaju/SE; como modificante: borracha de pneus inservíveis com granulometria inferior a 32 mesh, adquirida de empresas de recauchutagem de pneus da cidade de Itabaiana/SE e; borra oleosa de petróleo de fundo de tanque de armazenamento, cedida pela Petrobras/UO-SEAL; como aditivo de estabilidade de mistura de modificantes: argila bentonita, fornecida pela empresa Sonda Engenharia, argila caulinita comercial e óleo extensor NPA doado pela BR Químicos.

\subsection{Métodos}

A preparação da pré-mistura M1 foi realizada com $85 \% \mathrm{~m} / \mathrm{m}$ de borra oleosa de petróleo e $15 \% \mathrm{~m} / \mathrm{m}$ de borracha de pneu, a temperatura adotada durante a agitação mecânica foi de $160 \pm 5{ }^{\circ} \mathrm{C}$ e o tempo de processamento foi de 60 minutos.

Mediante a utilização de $10 \% \mathrm{~m} / \mathrm{m}$ da pré-mistura M1 em todas modificações do ligante e do uso dos aditivos NPA e argilas caulinita e bentonita, foram confeccionados os ligantes modificados CM1 (CAP modificado apenas por M1), CM1N1 (CAP modificado por M1 e $1 \% \mathrm{~m} / \mathrm{m}$ de NPA), CM1N2 (CAP modificado por M1 e $2 \%$ m/m de NPA), CM1N2 (CAP modificado por M1 e 3\% m/m de NPA), CM1C1 (CAP modificado por M1 e $1 \%$ m/m de argila caulinítica), CM1B1 (CAP modificado por M1 e $1 \% \mathrm{~m} / \mathrm{m}$ de argila bentonítica). Assim como na preparação da pré-mistura, a temperatura de processamento da modificação foi $160 \pm$ $5{ }^{\circ} \mathrm{C}$ e o tempo de agitação 60 minutos. 
Os ligantes, puro e modificado, e a borra oleosa foram caracterizados quanto ao comportamento reológico em modo permanente, utilizando o viscosímetro rotacional Brookfield.

A verificação da ocorrência de separação de fases foi realizada para todos os ligantes modificados. Quando realizada a modificação do ligante, este era vertido em molde cilíndrico de aço, com 30 mm de diâmetro e $150 \mathrm{~mm}$ de altura, e mantido em estufa por 48 horas na temperatura de $163^{\circ} \mathrm{C}$, em seguida, submetido ao resfriamento brusco em banho de gelo e salmoura. Após completo resfriamento, amostras foram retiradas da parte superior e inferior do molde e avaliadas as suas viscosidades comparativamente com o CAP $50 / 70$ puro, em viscosímetro Brookfield, spindle 21 , na faixa de temperatura de $175^{\circ} \mathrm{C}$ a $130^{\circ} \mathrm{C}$, para averiguar a existência ou não de separação de fase.

Constatado o ligante modificado de menor separação de fases o mesmo foi caracterizado quanto a adesividade aos agregados graúdo. Regulamentado pelo método de ensaio 078/98 do DNER, a avaliação qualitativa da adesividade do ligante asfáltico ao agregado é realizada pela mistura de $17,5 \mathrm{~g}$ de ligante a $500 \mathrm{~g}$ de agregado que passa na peneira de abertura $19 \mathrm{~mm}$ e retido na de abertura $12,7 \mathrm{~mm}$. A mistura agregado/ligante foi obtida com o agregado aquecido a $100^{\circ} \mathrm{C}$ e o ligante vertido sobre este a $120^{\circ} \mathrm{C}$. O agregado envolto pelo ligante foi colocado sobre uma superfície de vidro temperado e resfriado a temperatura ambiente. Em seguida a mistura foi colocada em béquer com água destilada e mantida em estufa a $40^{\circ} \mathrm{C}$ por 72 horas.

\section{RESULTADOS E DISCURSÕES}

Observa-se na Figura 1 que as curvas do comportamento da viscosidade dos CAPs modificados sem e com aditivos, obtidas em viscosímetro rotacional na temperatura de mistura $\left(170 \pm 5^{\circ} \mathrm{C}\right)$ apresentaram viscosidades inferiores à do CAP 50/70 puro. A viscosidade da blenda M1 não sofre variação na faixa de temperatura analisada.

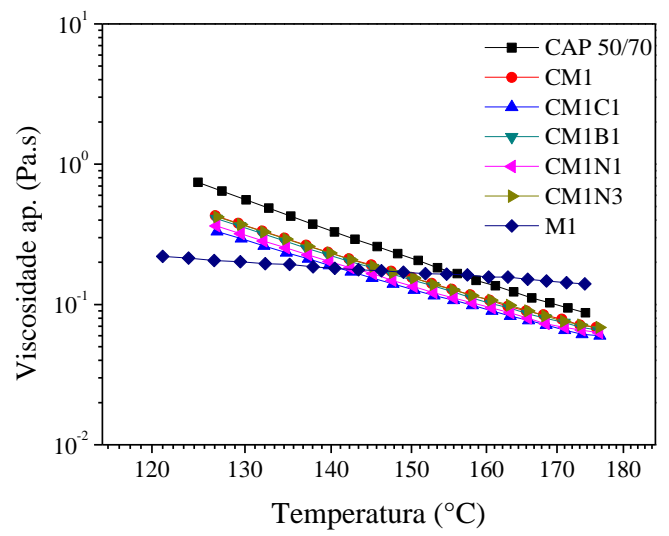

Figura 1: Viscosidade do ligante CAP 50/70 e CAP modificado com M1 e aditivos.

As Figuras $2(\mathrm{a}, \mathrm{b})$ mostram o comportamento das curvas de tensão de cisalhamento e de viscosidade com a taxa de cisalhamento do CAP 50/70 puro e modificado com a blenda M1, na presença de $1 \%$ do aditivo NPA. Observa-se na Figura 4a que o CAP 50/70 puro e o modificado CM1N1 apresentam comportamento de fluido Newtoniano, nas três temperaturas avaliadas, o que é confirmado pelo comportamento das curvas de viscosidade com a taxa de cisalhamento, como mostradas na Figura 2 b. 


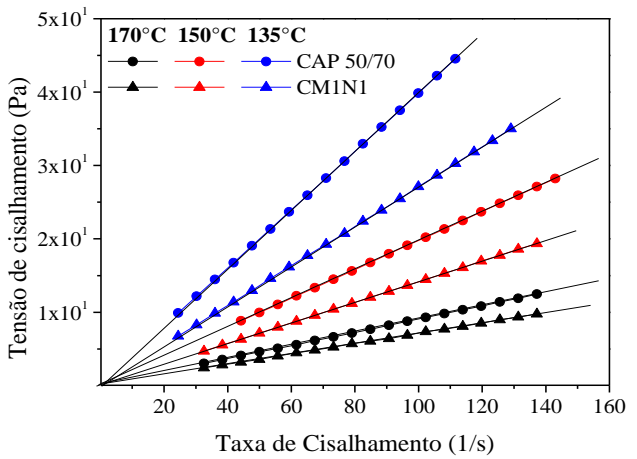

(a)

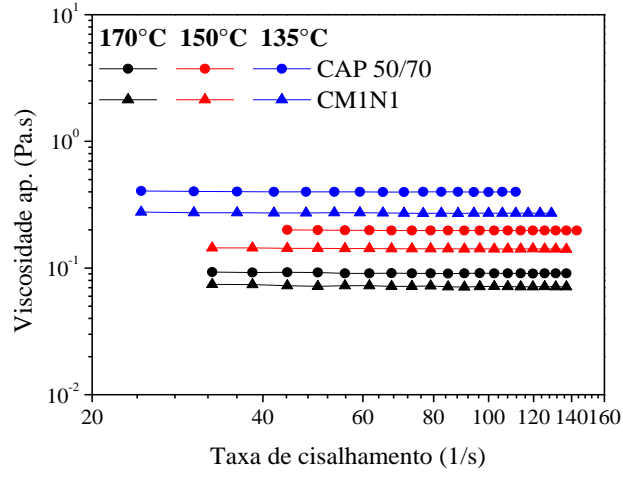

(b)

Figura 2: Curvas de tensão de cisalhamento e de viscosidade do ligante CAP 50/70 puro e modificado CM1N1: (a) curva de tensão de cisalhamento versus taxa de cisalhamento, (b) curvas de viscosidade versus taxa de cisalhamento.

As Figuras 3 (a, b, c, d, e, f), mostram os resultados dos ensaios de estabilidade de estocagem. Observa-se que as amostras de CAP modificado com NPA apresentaram melhores resultados de estocagem (separação de fase) em relação às demais amostras de CAP's modificados, pois as mesmas apresentaram menor afastamento entre as viscosidades das amostras retiradas do topo e do fundo do tubo cilíndrico de aço. Observa-se ainda, que o aumento da quantidade de NPA diminui a estabilidade de estocagem do ligante modificado CM1.

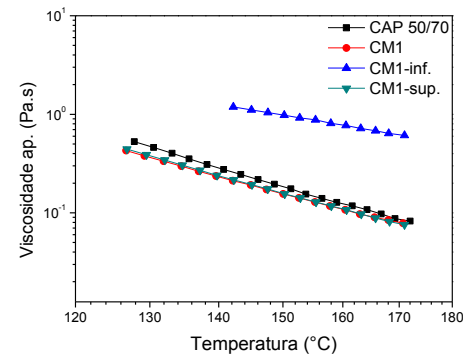

(a)

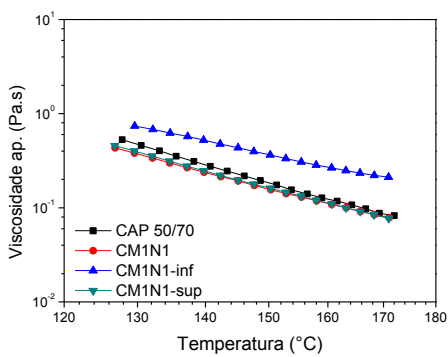

(d)

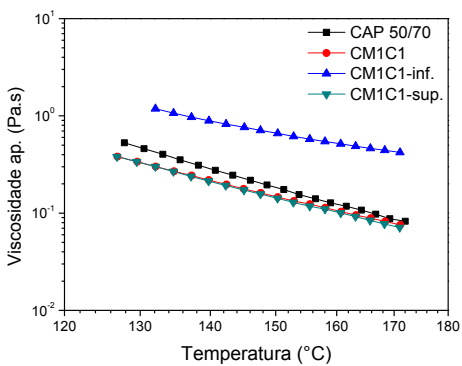

(b)

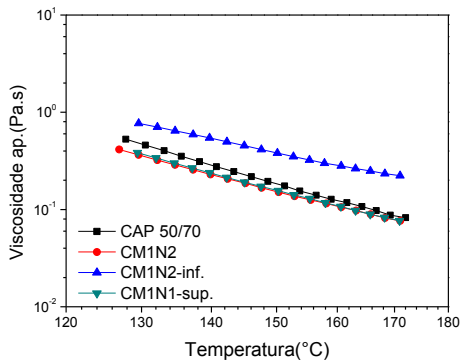

(e)

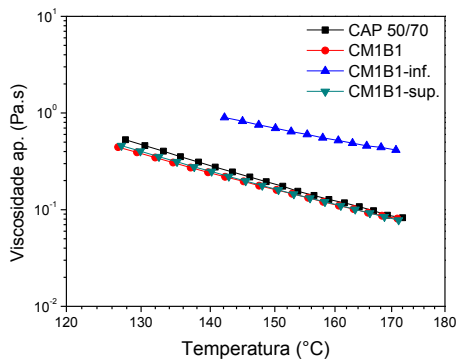

(c)

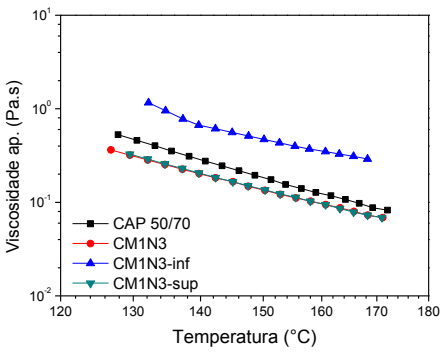

(f)

Figura 3: Curvas de viscosidade para o ensaio de Separação de fases (a) CM1 (b) CM1C1, (c) CM1B1, (d) CM1N1, (e) CM1N2, (f) CM1N3.

A Figura 4 mostra o índice de separação calculado pela razão das viscosidades, na temperatura de $150^{\circ} \mathrm{C}$, da amostra inferior pela amostra superior do tubo cilíndrico de aço, após o resfriamento da estocagem. O CAP 50/70 puro apresenta índice de separação igual a 1,0, ou seja, a viscosidade da base é igual a viscosidade do topo. Observa-se que o modificado com a blenda M1 e o aditivo NPA na concentração de $1 \% \mathrm{~m} / \mathrm{m}$ apresenta índice de separação mais próximo do valor da referência, o que concorda com o resultado mostrado na Figura 3 d. O que mostrou ter menor separação de fase. 


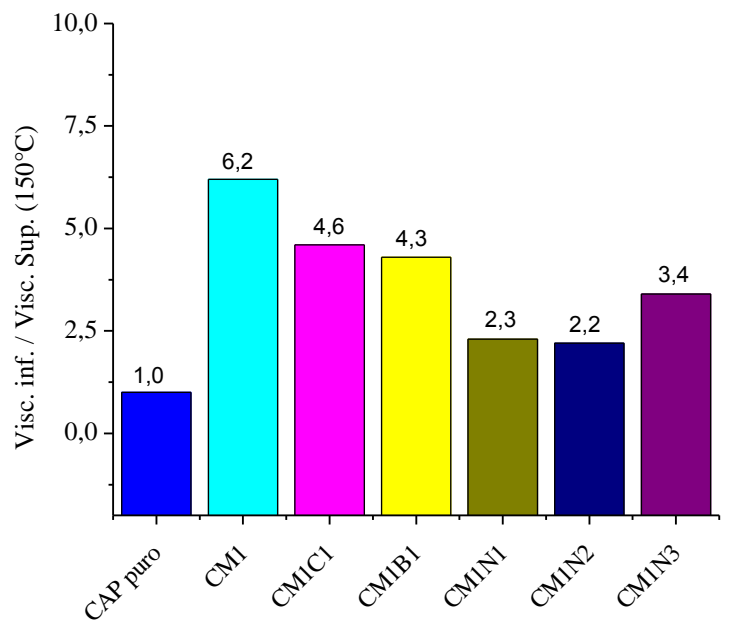

Figura 4: Índice de separação de fases do CAP 50/70 puro e modificado.

A Figura 5 mostra fotografia de agregados após ensaio qualitativo de adesividade do CAP 50/70 puro e modificado CM1N1. Observa-se que o agregado envolto com o ligante modificado CM1N1 apresentou maior uniformidade e boa adesão, sem descolamento da película, em relação ao agregado envolto com o ligante CAP 50/70 não modificado.

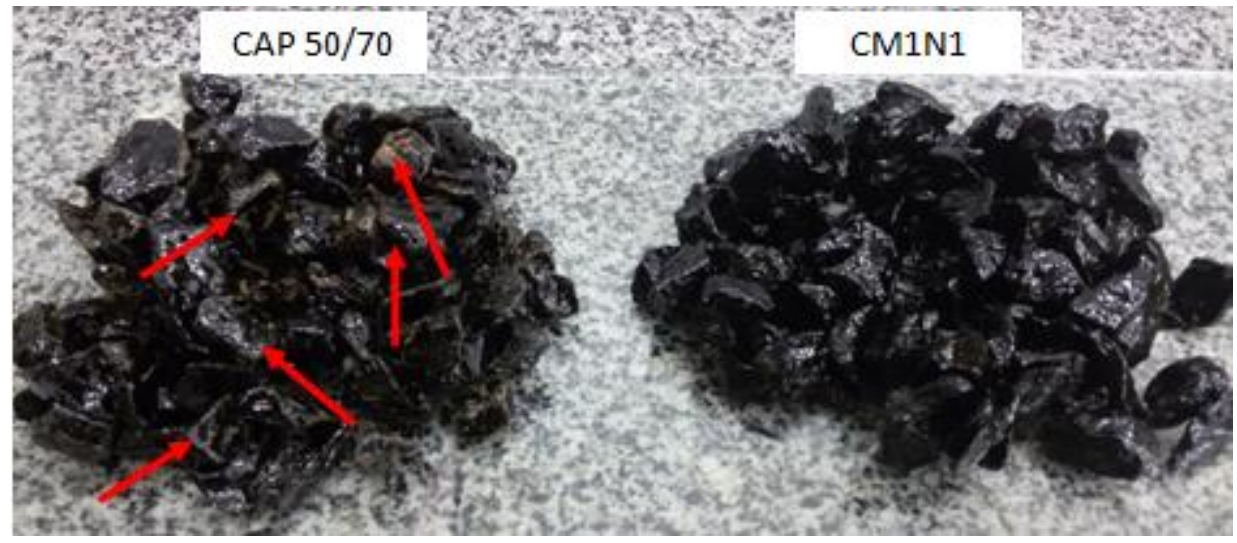

Figura 2: Avaliação qualitativa de adesividade do CAP 50/70 e modificado CM1N1

\section{CONCLUSÕES}

Os resultados mostram que a utilização de 1\% de NPA ao CAP 50/70 modificado com 10\% de M1 apresenta estabilidade de estocagem durante 48 horas e que a sua adesividade aos agregados é melhor do que a do CAP $50 / 70$.

\section{AGRADECIMENTOS}

Os autores agradecem as empresas EMURB/Aracaju, BR Químicos e Petrobras/UO-SEAL pelo fornecimento dos materiais utilizados neste trabalho.

\section{BIBLIOGRAFIA}

[1] CONFEDERAÇÃO NACIONAL DO TRANSPORTE - CNT - Relatório Gerencial: Pesquisa CNT de rodovias. Brasília, 2015.

[2] CONG P., XUN, P., XING M., et al., "Investigation of asphalt binder containing various crumb and asphalts”, Construction and Building Materials, v. 40, pp. 632-641, 2013. 
[3] DOMINGOS, M. D. I., FAXINA, A. L., "Comportamento fluência-recuperação de ligantes asfálticos modificados com copolímero SBR e ácido polifosfórico”, Transportes, v. 23, n. 2, pp. 56-64, 2015.

[4] FERNANDES, P. R. N., ALENCAR, A. E. V., SOARES, E. J. B., et al., "Estudo comparativo das propriedades químicas do resíduo borra oleosa asfáltica e do ligante asfáltico de petróleo", Holos, v. 29, n. 4, pp. 45-58, 2013.

[5] GRAÇA, D. C. S., CAVALCANTE, E. H., CARDOSO, G., "Dosagem de mistura asfáltica com CAP 50/70 modificado com borra de petróleo", Scientia Plena, v.12, n. 5, 2016.

[6] LIU, H., CHEN, Z., WANG, W., et al., "Investigation of the rheological modification mechanism of crumb rubber modified asphalt (CRMA) containing TOR additive", Construction and Building Materials, v. 67, pp. 225- 2014, 2013.

[7] ONOFRE, F. C., BRANCO, V. T. F. C., SOARES, J. B., et al., “Avaliação do efeito de ligantes asfálticos modificados na resistência à deformação permanente de misturas asfálticas densas”, Transportes, v. 21, n. 3, pp. 14-21, 2013.

[8] OUYANG, C., WANG, S., ZHANG, Y., et al., "Preparation and properties of styrene-butadiene-styrene copolymer/kaolinite clay compound and asphalt modified with the compound", Science Direct, v. 87, pp. 309-317, 2005.

[9] PAMPLONA, T. H., SOBREIRO, F. P., FAXINA, A. L., et al., "Propriedades reológicas sob altas temperaturas de ligantes asfálticos de diferentes fontes modificados com ácido polifosfórico", Transportes, v. 20, n. 4, pp.5-11, 2012.

[10] RODRÍGUEZ-ALlOZA, A. N., GALLEGO, J., PÉREZ, I., "Study of the effect of four warm mix asphalt additives on bitumen modified with 15\% crumb", Construction and Building Materials, v. 43, pp. 300308, 2013.

[11] SANTOS, K. P., LUCENA, A. E. F. L., LUCENA, L. C. F. L., et al., "Estudo da incorporação de argilas montmorilonitas em cimentos asfálticos de petróleo”, Revista Matéria, pp. 501-513, 2015.

[12] SILVA, L. J., ALVES, F. C., FRANÇA, F. P., "A review of the technological solutions for the treatment of oily sludges from petroleum refineries", Waste Management \& Research , v. 30, n. 10, pp. 1016-1030, 2012.

[13] SILVA, S. A. T., VIDAL, P. J. F., HOLANDA, A. S., et al., “Análise viscoelástica de pavimentos asfálticos utilizando elementos finitos e infinitos", Transportes, n. 21, v. 3, pp. 5-13, 2013.

[14] YU, R., FANG, C., LIU, P., et al., "Storage stability and rheological properties of asphalt modified with waste packaging polyethylene and organic montmorillonite", Applied Clay Science, v. 104, pp. 1-7, 2015. 